\title{
Iron Status in Chronic Renal Failure with Anemia
}

\author{
Shaheda Khanam ${ }^{1 *}$ \\ Noorzahan Begum² \\ AMM Ehteshamul Hoque ${ }^{3}$ \\ 'Department of Physiology, \\ Chattagram Maa-O-Shishu Hospital \\ Medical College, Chittagong \\ 2Department of Physiology, \\ BSMMU, Shahbag, Dhaka \\ ${ }^{3}$ Department of Nephrology, \\ Chattagram Maa-O-Shishu Hospital \\ Medical College, Chittagong
}

\section{*Correspondence to:}

Dr Shaheda Khanam

Associate Prof., Department of Physiology,

Chattagram Maa-O-Shishu Hospital Medical

College, Agrabad, Chittagong 4100,

Bangladesh

E-mail: dr.ehteshamcto@yahoo.com

\section{How to cite this article:}

Khanam S, Begum N, Hoque AMME. Iron status in chronic renal failure with anemia. Chatt Maa Shi Hosp Med Coll J 2013; 12(1): 12-17.

\begin{abstract}
Background: Chronic renal failure (CRF) is a major public health hazard. Anemia is an accompaniment and independent risk factor for the development of cardiac dysfunction and responsible for $40 \%$ to $50 \%$ deaths in CRF patients. For this reason, effective erythropoiesis to correct anemia by erythropoietin therapy and maintenance of target iron level is very much important. Subjects and Methods: The present study has been designed to observe iron status in different stages of CRF patients suffering from anemia. For this purpose, 65 male CRF patients with anemia and 25 healthy male (control) subjects, in the age group of 30-50 years were selected randomly from BSMMU outpatient department. Iron level, hemoglobin and creatinine clearance were estimated by usual laboratory technique. Data were analyzed statistically by ANOVA and Pearson's correlation coefficient test. Among 65 CRF patients, 15 were mild, 25 were moderate and 25 were reported severe renal failure with anemia. Results: The mean serum iron, transferrin saturation and ferritin were significantly $(P<0.001)$ lower in moderate but severe in CRF patients with anemia compared to those of healthy subjects and these values were also significantly $(P<$ $0.001)$ lower in severe CRF than those of mild and moderate groups of patients. On the other hand, total iron binding capacity was significantly $(P<0.001)$ higher only in severe group of CRF patients compared to healthy, mild and moderate group of CRF patients. In addition, $72 \%$ severe group of CRF patients had serum ferritin and $28 \%$ had transferrin saturation below the target level $(\geq 100 \mathrm{ng} / \mathrm{ml}$ serum ferritin \& $\geq 20 \%$ transferrin saturation). Decreasing iron status which is more marked in severe CRF patients are suggestive of iron deficiency and iron status below the target level in severe CRF patients indicate inadequate iron store. Also, a significantly $(P<0.001)$ decreasing hemoglobin concentration is observed in severe CRF case compared to those of mild and moderate CRF patients with anemia. Conclusion: From the present study it may be concluded that changes in iron status occur in CRF patients with anemia and these changes vary along with severity of CRF.
\end{abstract}

Key words: Hemoglobin; Iron; Renal failure.

\section{INTRODUCTION}

Chronic renal failure (CRF) is one of the major public health problems throughout the world. ${ }^{1}$ In Bangladesh, $5 \%$ of total population have been suffering from renal diseases, among them, about 15,000 to 20,000 patients are dying due to CRF each year. ${ }^{2}$ With progression of disease various abnormalities developed. ${ }^{3}$ Anemia is one of the most consistent and severe hematological complication in this group of 
population. ${ }^{4}$ CRF is associated with higher level of serum creatinine along with lower creatinine clearance and according to these values the disease can be categorized into mild, moderate and severe one. ${ }^{5}$ Normal serum iron concentration and total iron binding capacity has been observed in different stages of $\mathrm{CRF}^{6,7}$ In contrast, lower serum iron and higher TIBC were also reported in a few number of patients suffering from severe $\mathrm{CRF}^{4}$ Recently, more interest has been shown to assess iron status by measuring transferrin saturation and serum ferritin level, as transferrin saturation reflects the amount of iron immediately available for hemoglobin synthesis and ferritin reflects total body iron store. ${ }^{8}$ Again, it has also been reported that a target level of $\geq 100 \mathrm{ng} / \mathrm{ml}$ of serum ferritin and transferrin saturation of $\geq 20 \%$ should have to be maintained in CRF patients with anemia for effective erythropoiesis before erythropoietin therapy. Some investigators observed these values below target levels in some of the mild and moderate but in most of the cases of severe CRF patients suffering from anemia. ${ }^{9}$

In our country, a major number of kidney patients are suffering from CRF associated with anemia. ${ }^{2}$ Anemia is an independent risk factor for development of cardiac dysfunction like increased cardiac output, cardiac enlargement, left ventricular hypertrophy and congestive cardiac failure. In addition, it may decrease the quality of life and exercising capacity. ${ }^{8}$ Cardiovascular diseases account for $40 \%$ to $50 \%$ of deaths in CRF patients, and mortality rate in this group of patients are 15 times higher than that of general population. ${ }^{7}$ Again, earlier and effective correction of anemia in CRF patients may be helpful in preventing the development and subsequent progression of disease. Moreover, it may also increase the duration of pre-dialysis period and thereby decreases hospitalization. ${ }^{10}$ For correction of anemia with erythropoietin therapy, more importance has been given on detection of target level of ferritin and transferrin saturation. ${ }^{89}$ Again $70 \%$ of our population has been suffering from anemia due to iron deficiency. ${ }^{11}$ So early detection of iron status is more important for better management of CRF patients with anemia. Though various observations have been reported from different countries, no such study has yet been reported in our country regarding iron status in CRF patients along with the severity of disease. Therefore, the present study is designed to observe the iron status in different stages of CRF with anemia.

\section{MATERIALS AND METHODS}

The study was carried out to observe the iron status in patients with different stages of CRF. For this, 65 male CRF patients with anemia and 25 healthy male (control) subjects in the age group of 30-50 years were selected randomly. Among them 15 were mild, 25 were moderate and 25 were in severe group. The diagnosed CRF patients were taken from the outpatient Department of Nephrology, BSMMU, who fulfill the inclusion criteria-CRF patients with anemia hemoglobin concentration $<12 \mathrm{gm} / \mathrm{dl}$ and Ccr $30-50 \mathrm{ml} /$ $\mathrm{min}, \mathrm{Ccr} 16-29 \mathrm{ml} / \mathrm{min}$, Ccr 5-15 ml/min were respectively mild, moderate and severe CRF patients ${ }^{5,8}$ in the experimental group. Apparently healthy subjects were selected from kidney donor attending outpatient department of nephrology, BSMMU. CRF patients with history of kidney transplantation, associated liver disease, non-renal origin of anemia (previous history of GIT bleeding, malignancy, chronic TB), history of erythropoietin therapy and history of blood transfusion during the last three months ${ }^{6,12}$ were excluded from the study. After selection of the subjects, objectives and procedures of the study were explained and then verbal consent was obtained from the patient. Blood and urine samples were taken from each study subject for measurement of hemoglobin, biochemical parameters and creatinine clearance. Adequate amount of blood was taken for measurement of hemoglobin and rest was kept in standing position till it clotted. Then the serum was collected in a labeled test tube for measurement of serum creatinine, serum iron, total iron binding capacity and serum ferritin. A labeled plastic container was supplied to each of the study subject for collection of 24-hour urine. The 24-hour urine volume was measured. Then, $1 \mathrm{ml}$ of urine from this sample was taken into a cylinder for measurement of urinary creatinine concentration and from that creatinine clearance was measured.

Statistical analysis was done using ANOVA test and relationship between different parameters was done by Pearson's correlation coefficient test.

\section{RESULT}

The mean $( \pm \mathrm{SD})$ hemoglobin concentrations in control and CRF patients with anemia in different stages are shown in Table 1. The mean hemoglobin concentrations were significantly lower $(P<0.001)$ in mild, moderate and severe CRF patients compared to that of healthy subjects. Again this concentration was also significantly lower $(P<0.001)$ in severe than those of mild and moderate CRF patients and also in moderate than that of mild CRF patients. 
Table 1: Hemoglobin concentration in different stages of CRF patients with anemia and in healthy subjects $(n=90)$

\begin{tabular}{lcc} 
Groups & $\mathbf{n}$ & $\begin{array}{c}\text { Hemoglobin }(\mathbf{g} / \mathbf{d l l}) \\
\text { Mean }( \pm \text { SD })\end{array}$ \\
Control & 25 & $14.56 \pm 0.99$ \\
& & $(12.51-15.76)$ \\
Mild CRF & $10.85 \pm 0.65$ \\
& 15 & $(9.80-11.77)$ \\
Moderate CRF & $9.13 \pm 0.78$ \\
Severe CRF & 25 & $(7.50-10.57)$ \\
& & $7.39 \pm 1.01$ \\
& 25 & $(6.20-9.50)$ \\
\hline
\end{tabular}

Notes: Control $=$ healthy subjects, $\mathrm{CRF}=$ chronic renal failure, results are expressed as mean $( \pm \mathrm{SD})$; figures in parenthesis indicate range; $n=$ number of subjects.

The mean $( \pm \mathrm{SD})$ serum iron, transferring saturation values and serum ferritine levels in control and CRF patients with anemia in different stages are shown in Table 2.

The mean serum iron and ferritin level in moderate and severe CRF patients were significantly lower $(P<0.001)$ than that of healthy subjects. Again, in severe CRF patients these levels were significantly lowered $(P<0.001)$ than those of mild and moderate cases.

The mean \pm SD total iron binding capacities in healthy subjects \& in mild, moderate, severe CRF patients are shown in Table 3.

The mean total iron binding capacities in severe CRF patients was significantly higher $(P<0.001)$ than that of healthy subjects. Again, in severe CRF patients, total iron
Table 3: Total iron binding capacities

\begin{tabular}{lcc}
\multicolumn{1}{c}{ Groups } & $\boldsymbol{n}$ & $\begin{array}{c}\text { Total iron binding capacity } \\
(\boldsymbol{\mu m o l} / \mathrm{L} \\
\text { Mean }( \pm \text { SD) }\end{array}$ \\
\hline Control & 25 & $51.18 \pm 3.80$ \\
& & $(45.69-58.71)$ \\
Mild CRF & 15 & $51.53 \pm 1.68$ \\
Moderate CRF & 25 & $(48.99-53.70)$ \\
& & $51.80 \pm 1.58$ \\
Severe CRF & 25 & $(49.30-54.42)$ \\
& & $56.50 \pm 6.56$ \\
\end{tabular}

Notes: Control $=$ healthy subjects, $\mathrm{CRF}=$ chronic renal failure, $n=$ numbers of subjects.

binding capacity was significantly higher $(P<0.001)$ than those of mild and moderate CRF patients.

Frequency distribution of serum ferritin and transferring saturation were done in different stages of CRF with anemia and the results are shown in Tables 4 and 5.

Among the mild CRF patients, all (100\%) had ferritin level $>100 \mathrm{ng} / \mathrm{ml}$ and transferrin saturation $>20 \%$ in mild and also in moderate CRF cases. However, $12 \%$ out of 25 moderate cases had $<100 \mathrm{ng} / \mathrm{ml}$ serum ferritin level. Similarly, in severe CRF patients $28 \%$ had ferritin level $>100$ $\mathrm{ng} / \mathrm{ml}$, transferring saturation $<20 \%$ and again $72 \%$ had $<100$ $\mathrm{ng} / \mathrm{ml}$ serum ferritin level, $>20 \%$ transferrin saturation level.

\section{DISCUSSION}

The present study was undertaken to observe iron status in different stages of CRF patients suffering from anemia. For

Table 2: Serum iron, transferrin saturation, serum ferritin in different stages of CRF patients with anemia and in healthy subjects $(n=90)$

\begin{tabular}{lcccc}
\multicolumn{1}{c}{ Groups } & $\boldsymbol{n}$ & $\begin{array}{c}\text { Serum iron }(\boldsymbol{\mu} \text { mol/L) } \\
\text { Mean }( \pm \text { SD })\end{array}$ & $\begin{array}{c}\text { Transferrin saturation\% } \\
\text { Mean }( \pm \text { SD })\end{array}$ & $\begin{array}{c}\text { Serum ferritin }(\boldsymbol{\mu g} / \mathbf{L}) \\
\text { Mean }( \pm \text { SD })\end{array}$ \\
Control & 25 & $19.43 \pm 1.88$ & $37.71 \pm 3.95$ & $187.34 \pm 33.49$ \\
& & $(17.54-23.18)$ & $(30.12-47.27)$ & $(128.10-230.50)$ \\
Mild CRF & $15.46 \pm 1.27$ & $34.60 \pm 3.91$ & $170.11 \pm 31.27$ \\
& & $(15.75-20.05)$ & $(29.33-42.65)$ & $(118.00-200.40)$ \\
Moderate CRF & 25 & $17.26 \pm 1.65$ & $30.53 \pm 4.21$ & $148.06 \pm 34.86$ \\
& & $(14.03-19.12)$ & $(23.07-36.69)$ & $(97.50-188.50)$ \\
Severe CRF & 25 & $12.70 \pm 2.70$ & $23.18 \pm 6.75$ & $74.05 \pm 37.67$ \\
& & $(8.77-17.63)$ & $(11.78-33.98)$ & $(19.50-150.80)$ \\
\hline
\end{tabular}

Notes: Control $=$ healthy subjects, $\mathrm{CRF}=$ chronic renal failure, results are expressed as mean $( \pm \mathrm{SD}), n=$ number of subjects . 
Table 4: Frequency distribution of serum ferritin in different stages of CRF with anemia

\begin{tabular}{cccccc}
$\begin{array}{c}\text { Mild CRF } \\
(\boldsymbol{n}=15)\end{array}$ & $\begin{array}{c}\text { Moderate CRF } \\
(\boldsymbol{n}=25)\end{array}$ & $\begin{array}{c}\text { Severe CRF } \\
(\boldsymbol{n}=25)\end{array}$ \\
Ferritin $(\mathrm{ng} / \mathrm{ml})$ & $\begin{array}{c}\text { Ferritin }(\mathrm{ng} / \mathrm{ml}) \\
\text { Ferritin }(\mathrm{ng} / \mathrm{ml})\end{array}$ \\
$>100 \%$ & $<100 \%$ & $>100 \%$ & $<100 \%$ & $>100 \%$ & $<100 \%$ \\
100.00 & 0.00 & 88.00 & 12.00 & 28.00 & 72.00 \\
\hline
\end{tabular}

Table 5: Frequency distribution of transferring saturation in different stages of CRF with anemia

\begin{tabular}{cccccc}
$\begin{array}{c}\text { Mild CRF } \\
(\boldsymbol{n}=15)\end{array}$ & $\begin{array}{c}\text { Moderate CRF } \\
(\boldsymbol{n}=25)\end{array}$ & $\begin{array}{c}\text { Severe CRF } \\
(\boldsymbol{n}=25)\end{array}$ \\
$\begin{array}{c}\text { Transferrin } \\
\text { saturation\% }\end{array}$ & $\begin{array}{c}\text { Transferrin } \\
\text { saturation\% }\end{array}$ & $\begin{array}{c}\text { Transferrin } \\
\text { saturation\% }\end{array}$ \\
$>20 \%$ & $<20 \%$ & $>20 \%$ & $<20 \%$ & $>20 \%$ & $<20 \%$ \\
100.00 & 0.00 & 100.00 & 0.00 & 72.00 & 28.00 \\
\hline
\end{tabular}

Notes: $n=$ number of subjects, $\mathrm{CRF}=$ chronic renal failure.

this purpose, mild, moderate and severe CRF patients with anemia were studied and their iron status was measured by estimating serum iron, ferritin, TIBC and by calculating transferrin saturation along with the estimation of hemoglobin concentration. All these parameters were studied in age and sex matched with healthy subjects for control and also to find out their baseline data in this group of population. All the subjects belong to poor socio-economical status. In this study, hemoglobin and iron level in healthy subjects were within normal range. The mean hemoglobin concentration was significantly $(P<0.001)$ lower in moderate and severe than that of mild CRF and also between moderate and severe CRF patients suffering from anemia. These hemoglobin concentrations observed in moderate and severe cases were markedly lower in comparison to mild cases in this series of CRF patients with anemia. These results were also consistent with the findings reported by other investigators. ${ }^{6,7,9,13,14}$ The mean serum iron level in moderate and severe CRF cases with anemia compared to that of healthy subjects were statistically significant $(P<0.001)$. Similar lower level of serum iron was also observed in CRF patients. ${ }^{6}$ Again, serum iron level $(P<0.001)$ was significantly lower in severe than those of mild and moderate CRF patients with anemia. However this lower level was not statistically significant in moderate cases in comparison to that of mild group. Similar observation was also reported in severe CRF patients, ${ }^{4}$ while some other investigators also reported similar findings in moderate and severe CRF patients. ${ }^{13}$ The mean serum TIBC was higher in mild, moderate and severe CRF patients associated with anemia than that of healthy subjects though in all the groups it was within normal range. Similar findings were also observed by some workers. ${ }^{7}$ The differences of this level in severe CRF with anemia compared to that of healthy subjects were statistically significant $(P<0.001)$. Similar higher levels were also reported in similar groups of patients. ${ }^{6}$ Again, serum TIBC was significantly $(P<0.001)$ higher in severe than those of mild and moderate CRF patients associated with anemia. However, this higher level was not statistically significant in moderate cases in comparison to that of mild cases. Some workers also observed similar higher level in moderate and severe CRF. ${ }^{13}$ The mean transferrin saturations observed both in moderate and severe CRF patients with anemia to those of healthy subjects were statistically significant $(P<0.001)$. These are consistent with findings of some investigators. ${ }^{7}$ On the other hand, these mean levels were significantly $(P<0.001)$ lower in severe compared to those of mild and moderate CRF with anemia. However, the transferrin saturation observed in moderate cases compared to that of mild cases was not statistically significant. Again workers of different countries also observed similar lower transferring saturation in CRF with anemia patients, ${ }^{15}$ while others reported similar lower value in severe group of patients. ${ }^{16}$ The mean serum ferritin levels were lower in mild, moderate and severe CRF patients with anemia compared to that of healthy subjects. Though a tendency to decrease was observed, these levels were within normal range in all the three groups of CRF patients. Similar findings were also reported by some investigators. ${ }^{7}$ On the other hand, significant $(P<0.001)$ differences of this level were observed in severe cases compared to those of mild and moderate CRF. However, in moderate cases, statistically no significant difference was observed than that of mild CRF. Similar lower level was also reported by workers of different countries. ${ }^{9} 13$ While some investigators also found similar lower level in severe group of patients. ${ }^{15}$ The transferrin saturation of $\geq 20 \%$ and serum ferritin level $\geq 100 \mathrm{ng} / \mathrm{ml}$ is considered as a target level before erythropoietin therapy in CRF patients with anemia. In this study, transferrin saturation was above the target level in all (100\%) the mild and moderate CRF patients. On the other hand, serum ferritin level in moderate CRF with anemia $76 \%$ of the patients had above and $24 \%$ below this target level. Again, in $72 \%$ of the patients suffering from severe CRF had above, while $28 \%$ had below the target level of transferrin saturation. On the other hand, serum ferritin concentration, 28\% patients had above and $72 \%$ had below this target level. In a similar type of study, 
some workers reported that $19 \%$ of mild, $35 \%$ of moderate and $69 \%$ of severe CRF patients had transferrin saturation below the reference target level. ${ }^{8}$ Similar type of findings was also reported by investigators who observed $52 \%$ of severe had below the target level. ${ }^{17}$ Again, some investigators reported that $37 \%$ of mild, $44 \%$ of moderate and $44 \%$ of severe CRF patients had serum ferritin below the target level. ${ }^{9}$ Different investigators made various suggestions about the causes of this hemoglobin concentration changes in patients suffering from CRF.. Workers of different countries suggested that erythropoietin deficiency due to decline in functional renal tissue is a causative factor for decrease in $\mathrm{RBC}$ production in CRF patients suffering anemia. ${ }^{6,89}$ As anorexia, nausea and vomiting are the common features of CRF patients, less dietary intake of nutrients needed for erythropoiesis might also be responsible for anemia in this group of patients. Moreover, some investigators suggested that CRF patients are on protein-restricted diet which might also have some role for anemia in these series of patients. ${ }^{4}$ In supporting this explanation, iron deficiency may contribute to the development of anemia in severe CRF patients. ${ }^{8}$ Workers from different countries also suggested that various factors might be involved for lowering of iron status in patients suffering from CRF associated with anemia. These factors are possibly due to defective iron absorption, frequent blood test and also reduced dietary intake of iron as a consequence of gastrointestinal symptoms, like nausea, anorexia and vomiting. ${ }^{6,79}$ Again, in majority cases impaired platelet function may also contribute to deficiency of iron in patients suffering from severe CRF with anemia. ${ }^{18}$ It is further suggested that lower serum iron and normal serum levels may occur when severe CRF is associated with chronic infection. Some investigators also reported that for effective erythropoiesis by erythropoietin therapy, it is necessary to ensure sufficient availability of iron in patients suffering from CRF. ${ }^{8}$ They further suggested that serum ferritin level should be equal to or more than $100 \mathrm{ng} / \mathrm{ml}$ and transferrin saturation equal to or more than $20 \%$ for effective erythropoiesis in patients suffering from CRF with anemia.

In the present study, hemoglobin concentration gradually lowered from mild to moderate and was markedly lowered in severe CRF patients with anemia. Erythropoietin deficiency is the primary cause of anemia in CRF and the findings of this study are also in favor of gradual destruction of erythropoietin secreting cells of the kidney in different stages of CRF though it was not possible to measure their erythropoietin levels. In addition, markedly lowered hemoglobin concentration in severe CRF was also likely due to less dietary intake of iron and vitamins as most of them were suffering from GIT symptoms, like anorexia, nausea and vomiting and they were also socio-economically poor. Moreover, maximum restriction of dietary protein usually advised in CRF also plays a role for marked change of hemoglobin in this group. Lower serum iron, ferritin, transferrin saturation with higher total iron binding capacity in CRF patients are suggestive of iron deficiency. It is further supported by positive correlation of serum iron, ferritin, transferrin saturation and negative correlation of total iron binding capacity with creatinine clearance. Lowered iron observed in these series of CRF patients are likely to be due to defective iron absorption, less intake of iron containing diet and GIT symptoms. Factors affecting iron absorption was not studied in the CRF patients of the present series, but other factors supported by indirect evidences from the history. Again, iron status depends on the severity of CRF which is also indicated by significantly decreased level of serum iron, ferritin, transferrin saturation and also significantly higher level of TIBC in severe CRF patients. The level of serum ferritin \& transferrin saturation in severe cases was below the target level while only ferritin level in moderate CRF cases was below the target level which indicate inadequate iron status in patients of these series.

\section{CONCLUSION}

From the present study it may be concluded that changes in iron status occur in CRF patients with anemia and these changes vary with severity of CRF. To correct anemia maintenance of target iron level is very much important for effective erythropoiesis by erythropoietin therapy. Further study on large sample using bone marrow biopsy with iron staining is recommended. 


\section{REFERENCES}

1. Hsu CY, Bates DW, Kuperman GJ, Curhan GC. Relationship between hematocrit and renal function in man and woman. Kidney Int. 2001; 59:725-31.

2. Rashid HU. Haemodialysis: how to reduce cost. Bangladesh Renal J. 1989; 8(2):43-4.

3. Davison AM, Cumming AD, Swainson CP, Turner N. Diseases of the kidney and urinary system. In: Davidson's principles and practice of medicine. 8th ed. London: Harcourt Brace and Company; 1998. 433 p.

4. Sweny P, Farrington K, Moorhead JF. The kidney and its disorders. Oxford: Blackwell Scientific Publications; 1989. pp. 359-69.

5. Morris PJ. Chronic renal failure. In: Kidney transplantation. 5th ed. Philadelphia: WB Saunders Company; 2001. 32 p.

6. Kaye M. The anemia associated with renal disease. J Lab Clin Med. 1978;52:83-100.

7. Kasiske BL, Chavers B, Rosenberg M, Foley R, Swan S, Fogo A, et al. (editors). Association of level of GFR with anemia. Am J Kidney Dis. 2002;39(Suppl 1):S120-7.

8. Kasiske BL, Chaver B, Rosenberg M, Foley R, Swan S, Fogo A, et al. (editors). Anemia of chronic kidney disease. Am J Kidney Dis. 2001; 37(Suppl 1): S184-98.

9. Hsu CY, McCulloch CE, Curhan GC. Epidemiology of anemia associated with chronic renal insufficiency among adults in the United States: results from the Third National Health and Nutrition Examination Survey. J Am Soc Nephrol. 2002;13:504-10.

10. Macdougall IC. How to improve survival in predialysis patients. J Nephron. 2000;85(Suppl 1): S15-22.

11. Saha AR, Ahmed AK. Anemia in two rural Bangladeshi communities with and without the supply of safe drinking water. Bangladesh J Nutri. 1991;4(1):1-8.

12. Loge JP, Lange RD, Moore CV. Characterization of the anemia associated with chronic renal insufficiency. Am J Med. 1978;24:4-18.

13. Silverberg DS, Laina A, Peer G, Kaplan E, Levin BA, Frank N, et al. Intravenous iron supplementation for the treatment of the anemia of moderate to severe chronic renal patients not receiving dialysis. Am J Kidney Dis. 1996;27:234-8.

14. Jungers P, Choukroun G, Oualim Z, Robino C, Nguyen AI, Man NK. Beneficial influence of recombinant human erythropoietin therapy on the rate of progression of chronic renal failure in pre dialysis patients. J Nephrol Dial Transplant. 2001;16:307-12.

15. Astor BC, Munter P, Levin A, Eustace JA, Coresh J. Association of kidney function with anemia. J Arch Intern Med. 2002;162:1401-8.

16. Shaheen FAM, Zazgornil J, Bough F, Iftikher A, Badawi L, AI-Aquil N. Iron status in chronic hemodialysis patients. Saudi Kidney Dis Transplant Bull. 1990;1:10-14.

17. Huchison FN, Jones WJ. A cost-effectiveness analysis of anemia screening before erythropoietin in patients with end stage renal disease. Am J Kidney Dis. 1997;29:651-7.

18. Erslev AJ. Anemia of chronic renal disease. Arch Intern Med. 1970;126:774-80. 